\title{
Characterization of an Antihypertensive Angiotensin I-Converting Enzyme Inhibitory Peptide from the Edible Mushroom Hypsizygus marmoreus
}

\author{
Min-Gu Kang, ${ }^{1}$ Young-Hun Kim, ${ }^{1}$ Zanabaatar Bolormaa, ${ }^{1}$ Min-Kyung Kim, \\ Geon-Sik Seo, ${ }^{2}$ and Jong-Soo Lee ${ }^{1}$ \\ ${ }^{1}$ Department of Biomedicinal Science and Biotechnology, PaiChai University, Daejeon 302-735, Republic of Korea \\ ${ }^{2}$ Korea National College of Agricultural and Fishery, Hwasung, Kyonggi-do 445-893, Republic of Korea
}

Correspondence should be addressed to Jong-Soo Lee; biotech8@pcu.ac.kr

Received 14 June 2013; Accepted 4 September 2013

Academic Editor: Youngjun Choi

Copyright (C) 2013 Min-Gu Kang et al. This is an open access article distributed under the Creative Commons Attribution License, which permits unrestricted use, distribution, and reproduction in any medium, provided the original work is properly cited.

\begin{abstract}
Hypertension is one of the very serious diseases and, recently, hypertensive patient longevity has been increased significantly. Therefore, the development of new antihypertensive drugs or bioactive compounds is very important to remedy or prevent hypertension. The antihypertensive angiotensin I-converting enzyme (ACE) inhibitor in water extracts from the brown-cultivarfruiting-body of Hypsizygus marmoreus was purified with ultrafiltration, $\mathrm{C}_{18}$ solid phase extraction chromatography and reversephase HPLC, and the purified ACE inhibitor with inhibitory activity of IC $_{50}$ value of $0.19 \mathrm{mg} / \mathrm{mL}$ was obtained. The purified ACE inhibitor was found to be a new oligopeptide with the sequence LSMGSASLSP. Its molecular weight was estimated to be $567.3 \mathrm{Da}$ and the water extracts containing ACE inhibitor from Hypsizygus marmoreus showed a clear antihypertensive action a spontaneously hypertensive rat.
\end{abstract}

\section{Introduction}

Hypsizygus marmoreus (family Tricholomataceae) is an edible fungus (Basidiomycetes) with a delicious taste and unique texture. It is found in Korea, Japan, China, North Europe, and East Asia. It generally grows well in the stumps of beech, maple, and blighted trees. Recent studies have demonstrated that this species provides antitumor and antioxidant effects. Its antitumor polysaccharide, $\beta$-(1-3)-D-glucan has an anticancer activity [1]. Mori et al. [2] reported that a dietary supplement containing $H$. marmoreus powder lowered total serum cholesterol and had a strong antiatherosclerotic effect. There was also an antioxidant effect [3, 4], and $\beta$-(1-3)D-glucan isolated from $H$. marmoreus showed very high antitumor activity [5].

Many antihypertensive, angiotensin I-converting enzyme (dipeptidyl carboxy peptidase I, kinase II, E.C 3.4.15.1, ACE) inhibitors have been identified in various microorganisms including Saccharomyces cerevisiae [6], Grifola frondosa [7],
Ganoderma lucidum [8], Tricholoma giganteum [9], Pholiota adiposa [10], and Pleurotus cornucopiae [11], ACE inhibitors have also been isolated from food and the enzymatic digestives of food proteins including, gelatin, casein, fish, fig tree latex, a-zein [12], sake and its byproducts [13], Korean traditional rice wines and liquors [14], and cereals and legumes [15]. Although many natural and synthetic ACE inhibitors (e.g., captopril, enalapril, and lisinopril), are effective as antihypertensive drugs, they also have some disadvantages, such as easy digestion by protease in the body, and side effects, such as coughing, allergies, taste disturbances, and skin rashes [6]. Therefore, the development of new ACE inhibitors that have strong antihypertensive activity, and resistance to digestion by various proteases; without side effects, is necessary. In a previous paper [16], we reported on the production of Hypsizygus marmoreus. In this study, an ACE inhibitor from the brown-cultivarfruiting-body of $H$. marmoreus was purified and characterized. 


\section{Methods}

2.1. Preparation of Hypsizygus marmoreus Extracts. Dried fruiting bodies $(50 \mathrm{~g})$ of $\mathrm{H}$. marmoreus (brown cultivar) containing antihypertensive ACE inhibitor were pulverized, added to $1.5 \mathrm{~L}$ water, and shaken at $50^{\circ} \mathrm{C}$ for $12 \mathrm{~h}$. The mixtures was centrifuged at $5000 \times \mathrm{g}$ for $30 \mathrm{~min}$ and filtered with a Whatman No. 41 filter paper and $0.45 \mu \mathrm{m}$ pore size filter (Nalgene, USA). The supernatant was lyophilized and used as a water extract.

2.2. Assay of ACE Inhibitory Activity. The ACE inhibitory activity was assayed by the modified method of Cushman and Cheung [17]. A mixture containing $100 \mathrm{mM}$ sodium borate buffer ( $\mathrm{pH} 8.3$ ), $300 \mathrm{mM} \mathrm{NaCl}, 150 \mu \mathrm{L}$ (3 units) of ACE from rabbit lungs, and $50 \mu \mathrm{L}$ of sample solution was preincubated for $10 \mathrm{~min}$ at $37^{\circ} \mathrm{C}$. The reaction was initiated by adding $50 \mu \mathrm{L}$ of Hip-His-Leu at a final concentration of $5 \mathrm{mM}$. It was terminated after $30 \mathrm{~min}$ of incubation by the addition of $250 \mu \mathrm{L}$ of $1.0 \mathrm{M} \mathrm{HCl}$. The liberated hippuric acid was extracted with $1 \mathrm{~mL}$ of ethyl acetate, and $0.8 \mathrm{~mL}$ of the extract was evaporated using a Speed Vac Concentrator (EYELA Co., Japan). The residue was then dissolved in $1 \mathrm{~mL}$ of sodium borate buffer. Absorbance at $228 \mathrm{~nm}$ was measured to estimate the ACE inhibitory activity. The inhibition activity was calculated using

$$
\text { inhibition activity }(\%)=\left(1-\frac{A-B}{C-D}\right) \times 100 \text {, }
$$

where $A$ is the absorbance of the solution containing ACE, substrate and sample, $B$ is the absorbance of the solution containing ACE and sample without the substrate, $C$ is the absorbance of the solution containing ACE and substrate without the sample, and $D$ is the absorbance of the solution containing only substrate.

The concentration of the ACE inhibitor required to inhibit $50 \%$ of the ACE activity under the above assay condition was defined as $\mathrm{IC}_{50}$.

2.3. Purification of ACE Inhibitor. The water-extract solution was subjected to ultrafiltrate in with 50,000 and 5,000 M.W. cutoff filters (Labscale TFF System, Millipore Co., USA), and the ACE inhibitory activities of the filtrates and solutions of the filter-cake were determined. The active fraction was treated with three kinds of proteases (pepsin, trypsin, and pancreatin). The active fraction was lyophilized and applied to a $\mathrm{C}_{18}$ solid-phase extraction (Sep-Pak $\mathrm{C}_{18}$ Cartridges, Waters Co., Milford, MA, USA), equilibrated with $5 \%$ acetonitrile. A gradient was carried out in water from $5 \%, 25 \%$, $50 \%$ and $100 \%$. The active fraction was lyophilized and it was applied to a strong cation exchange (SCX), solid-phase, extraction process (Hypersep SCX, Thermo Scientific Co., MA, USA), equilibrated with $10 \mathrm{mM}$ ammonium formate, and eluted with ammonium formate $(10,30,50,100$, and $200 \mathrm{mM}$ ). The active fraction obtained was then applied to reverse-phase, high-performance, liquid chromatography (RP-HPLC) (Vydac 218TP54, $\mathrm{C}_{18}$ column, $5 \mu \mathrm{m}, 4.6 \times$ $250 \mathrm{~mm}$, Discovery Science Co., USA), equilibrated with 5\% acetonitrile. A linear gradient (from 5 to $25 \%$ water) was carried out with $0.1 \%$ trifluoroacetic acid (TFA). The active fractions were collected and lyophilized immediately.

2.4. Antihypertensive Action of the Purified Ace Inhibitor. Spontaneously hypertensive male rats (SHR, SHR/NCrljOri) of body weight 190-220 $\mathrm{g}$ and nine weeks old were purchased from Samtaco Bio-Korea Co. (Korea, Osan City). SHRs were housed individually in steel cages in a room at $24^{\circ} \mathrm{C}$ with a $12 \mathrm{~h}$ light-dark cycle, and fed a standard diet. Tap water was freely available. Water extract of the $H$. marmoreus fruiting body was dissolved in saline at a dose of $800 \mathrm{mg} / \mathrm{kg}$ body weight and injected orally in SHRs. The systolic blood pressure of the animals was measured before and after $0,2,4,6$, and $8 \mathrm{~h}$ of administration by the rat tail-cuff method using a specially devised Blood Pressure Monitoring System (CODA Monitor, Kent Scientific Co., Torrington, CT, USA).

Each experimental group consisted of five SHRs. Negative and positive control groups were also used. The positive control group was administered the commercial antihypertensive drug Captopril (ACE inhibitor), at a dose of $100 \mathrm{mg} / \mathrm{kg}$, whereas saline was administered to the negative control group. Prior to treatment of the SHRs, blood was measured. While the ACE inhibitor was being administered, the blood pressure of members of each group was measured three times during every test.

\section{Results}

3.1. Purification of the ACE Inhibitor. After the water extracts of $H$. marmoreus (brown cultivar) were ultrafiltered with a 5000 M.W. cutoff filter, the ACE inhibitory activity of two filtrates were then determined. The ACE inhibitory activity of 5000 M.W. over filtrates was $7.1 \mathrm{mg} / \mathrm{mL}$ and 5000 M.W. below filtrates showed $6.4 \mathrm{mg} / \mathrm{mL}$ of $\mathrm{IC}_{50}$ ACE inhibitory activity. When the active 5000 M.W. below filtrates was treated with some proteases, pepsin treatment resulted in higher ACE inhibitory activity ( IC $_{50} ; 4.3 \mathrm{mg} / \mathrm{mL}$ ) than the other trypsin treatment $\left(\mathrm{IC}_{50} ; 8.7 \mathrm{mg} / \mathrm{mL}\right)$ and pancreatin treatment $\left(\mathrm{IC}_{50} ; 20.0 \mathrm{mg} / \mathrm{mL}\right)$; data is not shown. The effect of pepsin treatment on ACE inhibitor in this study was similar to that of ACE inhibitor from Saccharomyces cerevisiae [6].

After $\mathrm{C}_{18}$ solid-phase extraction from $5 \%$ to $100 \%$ using acetonitrile, the fraction F1-2 from the extraction with 25\% acetonitrile showed high $\mathrm{IC}_{50}: 0.57 \mathrm{mg} / \mathrm{mL}$ of ACE inhibitory activity. After SCX solid-phase extraction of the active fraction by $10-200 \mathrm{mM}$ of ammonium formate, the active fraction (F1-2-1) from an extraction of $50 \mathrm{mM}$ ammonium formate, $0.36 \mathrm{mg} / \mathrm{mL}$ of $\mathrm{IC}_{50}$ was obtained (data not shown). Subsequently, RP-HPLCs were performed on the active fraction the using a l-Vydac-protein/peptide reverse-phase 218TP column and a purified ACE inhibitor showing ACE inhibitory activity $\left(\mathrm{IC}_{50}\right)$ of $0.34 \mathrm{mg} / \mathrm{mL}$ was obtained (Figure 1 ).

The inhibitory activity of the purified ACE inhibitor was lower than those of the mushrooms, Tricholoma giganteum ( $\mathrm{IC}_{50} 0.04 \mathrm{mg} / \mathrm{mL}$ ) [9], Pholiota adiposa ASI $24012(0.044 \mathrm{mg} / \mathrm{mL})$ [10], yeast: Saccharomyces cerevisiae 


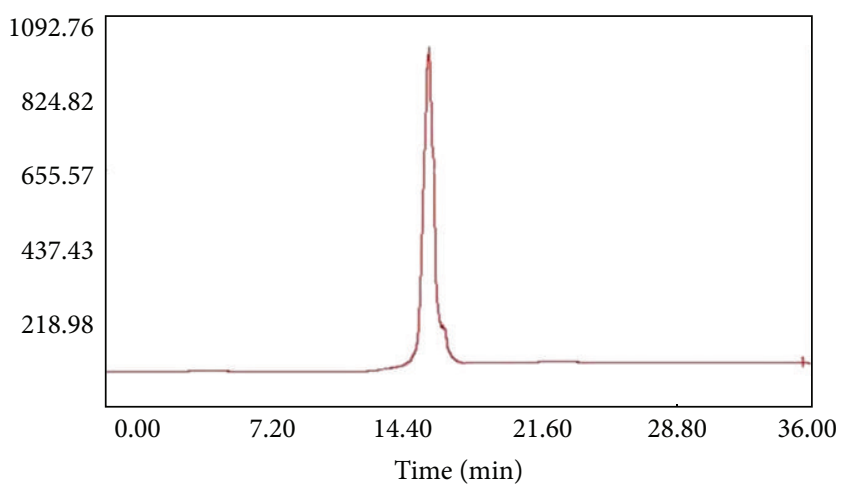

FIGURE 1: RP-HPLC chromatogram on 1 Vydac protein/peptide reverse-phase 218TP column of active fraction F1-2-3 (50 mM). Separation was performed with a linear gradient of acetonitrile containing $0.1 \%$ TFA from $5 \%$ to $25 \%$ at a flow rate of $1 \mathrm{~mL} / \mathrm{min}$.

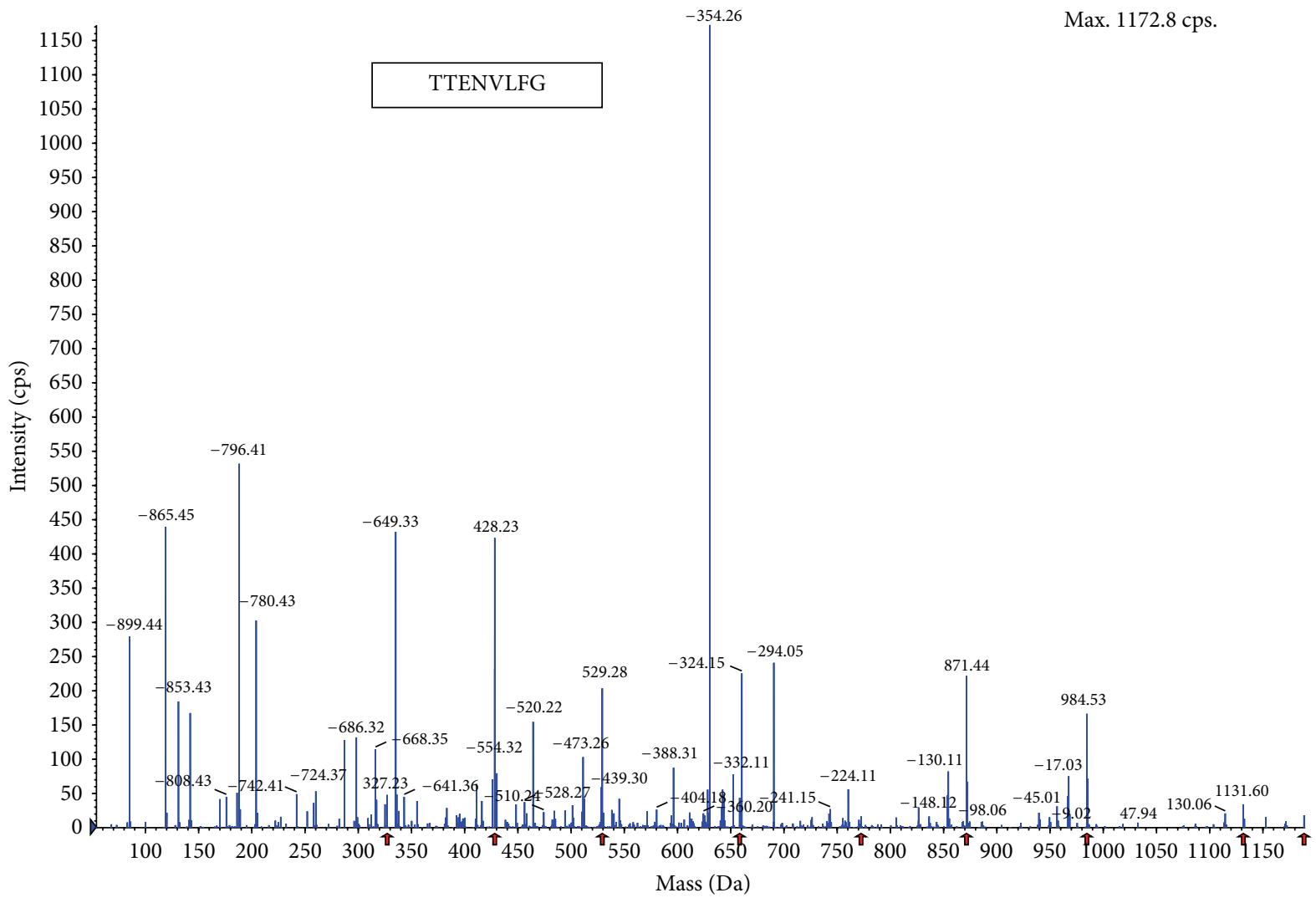

- Mass reconstruction of + TOF product (660.3):

exp 22, 45.730 to $46.832 \mathrm{~min}$ from sample 2 (msms) of $11 \mathrm{~ms}$ 106.wiff

FIGURE 2: Amino acid sequence of the purified oligopeptide (P-1) from H. marmoreus by LC-MS/MS. MS/MS experiments were performed on a LCQ-Deca ESI ion trap mass spectrometer (Thermo Finnigan Co., USA). For protein identification, the MS/MS spectra were searched using SEQUEST (ver 3.3) software. (P-1, TTENVLFG).

$(0.07 \mathrm{mg} / \mathrm{mL})$ and captopril, an antihypertensive drug which was chemically synthesized $\left(\mathrm{IC}_{50}: 0.004 \mathrm{mg} / \mathrm{mL}\right)$ [9].

\subsection{Analysis of Amino Acid Sequence and Molecular Weight.}

The purified ACE inhibitor was analyzed by LC-MS/MS and three kinds of oligopeptide (i.e., TTENVLFG (P-1), LSMGSASLSP (P-2) and LVNDLVTPVFDNL (P-3)) were obtained (Figures 2, 3, and 4). After chemically synthesizing these three oligopeptides, their ACE inhibitory activities were determined. Chemically synthesized oligopeptides had inhibitory activity $\left(\mathrm{IC}_{50}\right)$ of $3.03 \mathrm{mg} / \mathrm{mL}(\mathrm{P}-1), 0.19 \mathrm{mg} / \mathrm{mL}$ (P2) and $4.00 \mathrm{mg} / \mathrm{mL}(\mathrm{P}-3)$, respectively. Thus, we successfully identified the P-2 oligopeptide as the purified ACE inhibitor.

Meanwhile, the molecular weight of the purified ACE inhibitor P-2 was estimated to be $567.3 \mathrm{Da}$ without any 


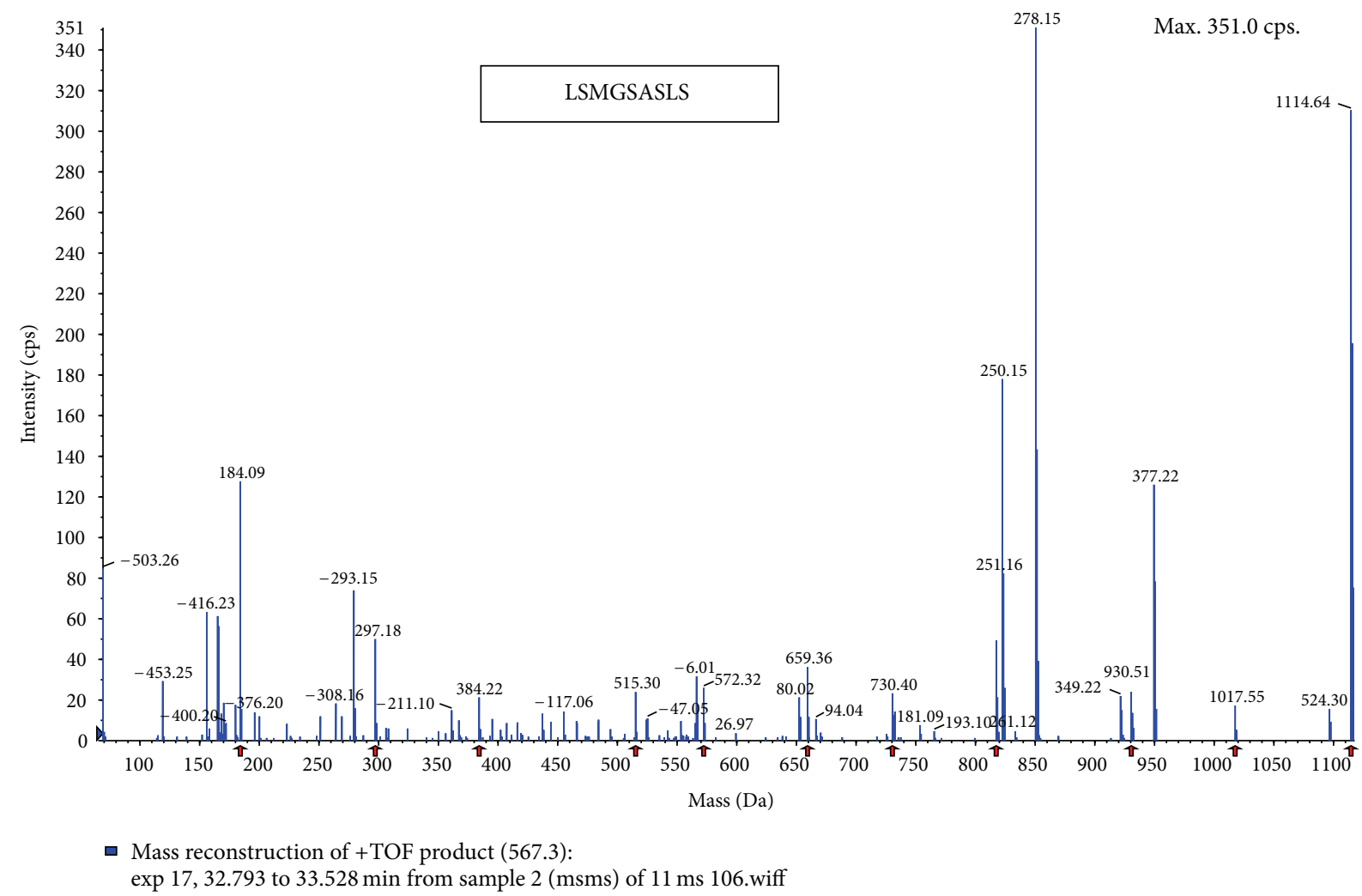

FIGURE 3: Amino acid sequence of the purified oligopeptide (P-2) from H. marmoreus by LC-MS/MS. MS/MS experiments were performed on a LCQ-Deca ESI ion trap mass spectrometer (Thermo Finnigan Co., USA). For protein identification, the MS/MS spectra were searched using SEQUEST (ver 3.3) software. (P-2, LSMGSASLSP).

TABLE 1: Comparison of sequence and ACE inhibitory activity between ACE inhibitory peptides from some mushrooms and Hypsizygus marmoreus in this study.

\begin{tabular}{lcccc}
\hline Mushrooms & Peptide & Molecular weight $(\mathrm{Da})$ & $\mathrm{IC}_{50}(\mathrm{mg} / \mathrm{mL})^{\mathrm{a}}$ & References \\
\hline Pleurotus cornucopiae & RLPSEFDLSAFLRA & 1622.85 & 0.460 & Jang et al. 2011 [11] \\
& RLSGQTIEVTSEYLFRH & 2037.26 & 1.140 & Koo et al. 2006 [10] \\
Pholiota adiposa & GOGGP & 414.00 & 0.044 & Lee et al. 2004 [9] \\
Tricholoma giganteum & GOP & 301.10 & 0.040 & 0.190 \\
Hypsizygus marmoreus & LSMGSASLSP & 567.30 & $17.9 \mathrm{nM}$ & This study \\
\hline Captopril & & & commercial drug \\
\hline
\end{tabular}

${ }^{\mathrm{a}}$ The concentration of an ACE inhibitor required to inhibit $50 \%$ of ACE activity.

homology. Its molecular weight was also similar to, or smaller than, those of the other ACE inhibitors from mushrooms Pholiota adiposa (414.0 Da) [10], Pleurotus cornucopiae (1622.85 Da, 2037.26 Da) [11], and Tricholoma giganteum (301.10 Da) [9]. See Table 1.

3.3. Determination of ACE Inhibition Pattern. The inhibitory pattern of the purified ACE inhibitor P-2 was investigated using a Lineweaver-Burk plot (Figure 5). It was found that the purified ACE inhibitor had a noncompetitive inhibitory pattern, unlike those of Grifola frondosa [7] and Tricholoma giganteum [9], which showed patterns of competitive inhibition.
3.4. Antihypertensive Action of the Purified Ace Inhibitor. The antihypertensive action of water-extracts from $H$. marmoreus was investigated using spontaneously hypertensive rats (SHRs).

As shown in Figure 6, the average blood pressure of the SHRs in the test group was approximately $180 \mathrm{mmHg}$ just before the administration of the water extracts containing ACE inhibitor. Two hours after administration to the rats of the water extract (dosage $800 \mathrm{mg} / \mathrm{kg}$ ), their blood pressure decreased to $154 \mathrm{mmHg}$, and after $4 \mathrm{~h}$, the average blood pressure increased to $166 \mathrm{mmHg}$. The average blood pressure of the positive control group increased $6 \mathrm{~h}$ after administration. This tendency of reduced blood pressure in SHR $4 \mathrm{~h}$ after oral administration was similar to that of the 


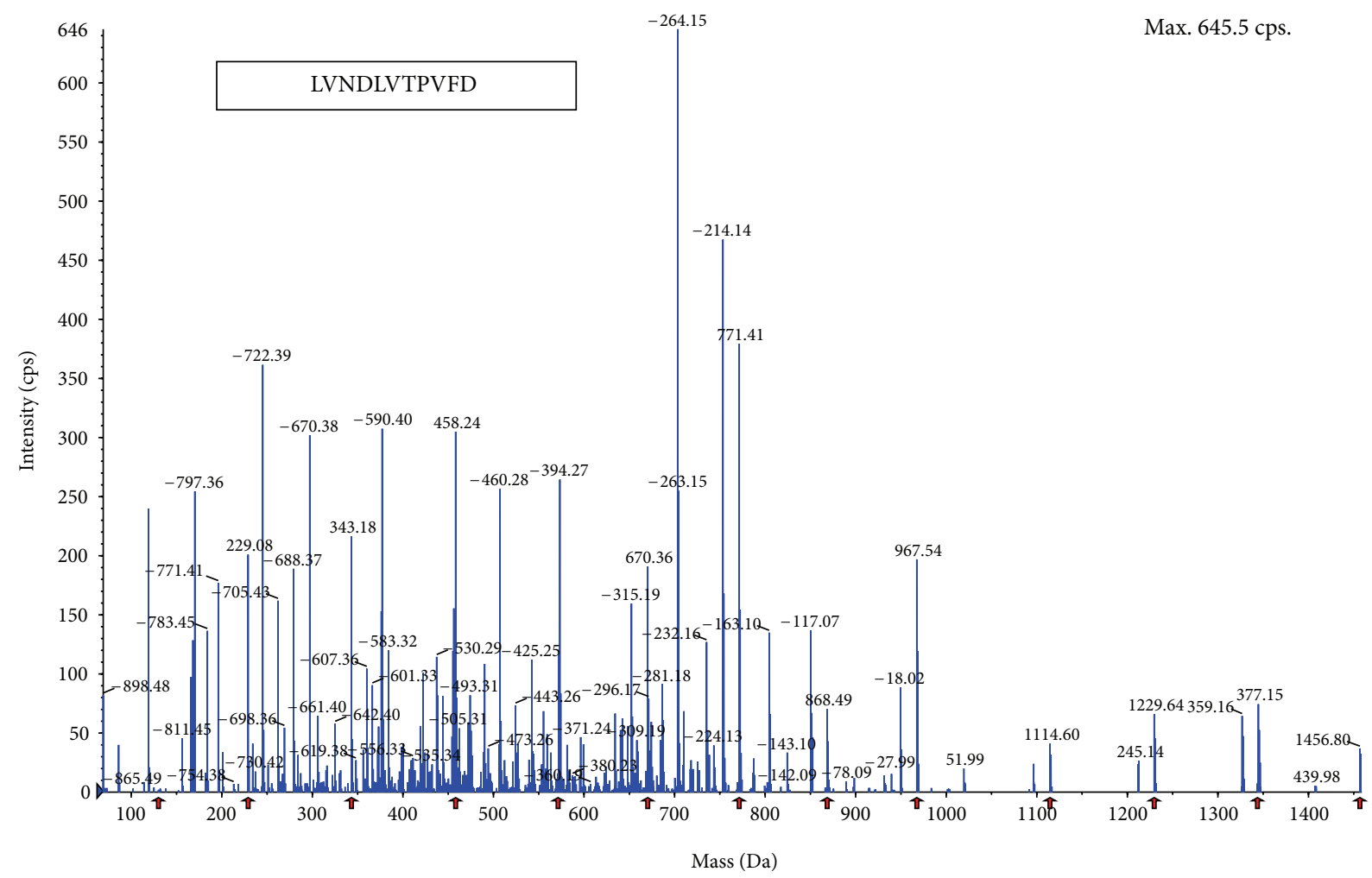

- Mass reconstruction of + TOF product (738.4):

exp 8, 41.824 to $42.191 \mathrm{~min}$ from sample 2 (msms) of $11 \mathrm{~ms} 106$. wiff

FIGURE 4: Amino acid sequence of the purified oligopeptide (P-3) from H. marmoreus by LC-MS/MS. MS/MS experiments were performed on a LCQ-Deca ESI ion trap mass spectrometer (Thermo Finnigan Co., USA). For protein identification, the MS/MS spectra were searched using SEQUEST (ver 3.3) software. (P-3, LVNDLVTPVFDNL).

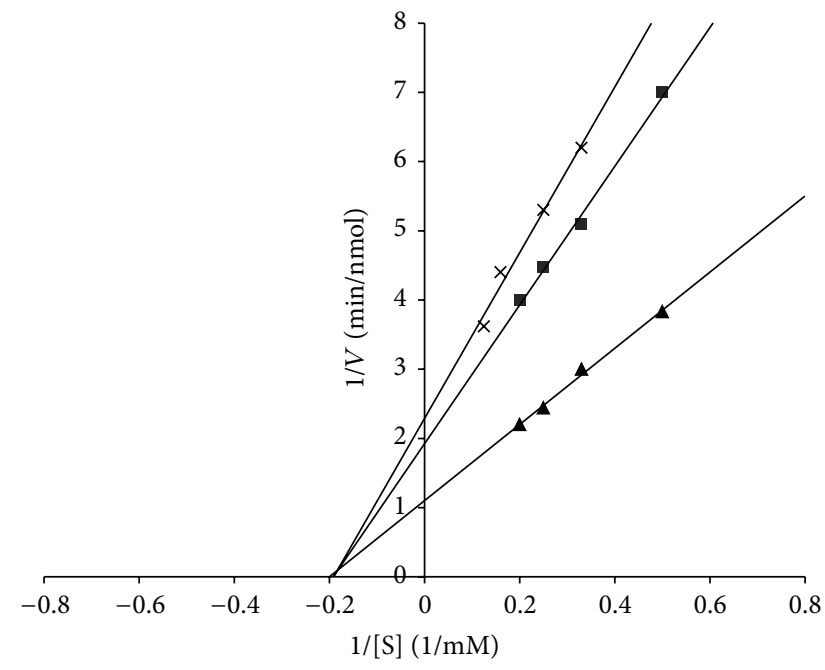

FIGURE 5: Lineweaver-Burk plot of ACE activity in the presence of the purified ACE inhibitor (P-2). ( $\mathbf{\Delta}$; Control, $\mathbf{\square} ; 0.1 \mathrm{mg}$ of inhibitor, $\times ; 0.3 \mathrm{mg}$ of inhibitor).

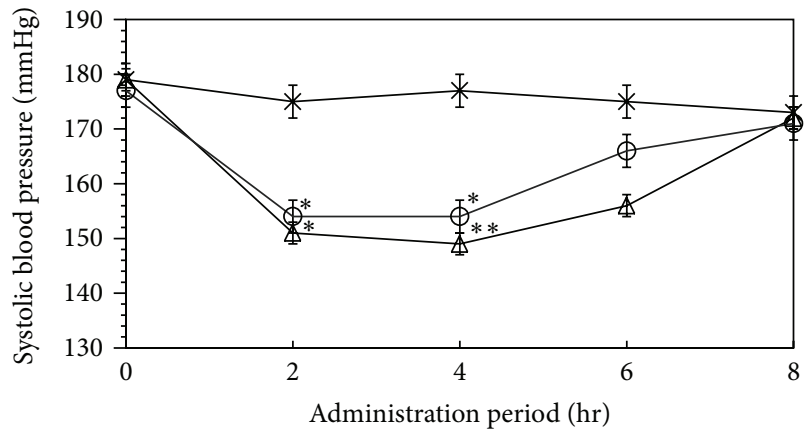

FIGURE 6: Changes in systolic blood pressure (SBP) of spontaneous hypertensive rat by administering water extract of Hypsizygus marmoreus. Single oral administration was performed with a dosage of $800 \mathrm{mg} / \mathrm{Kg}$ body weight, and SBP was measured after $0,2,4$, and $6 \mathrm{~h}$ administration. Different from control at ${ }^{*} P<0.05,{ }^{* *} P<0.01$. $\times$, Saline solution; $\triangle$, Commercial captopril; $\circ$, Water extract of Hypsizygus marmoreus containing antihypertensive angiotensin Iconverting enzyme inhibitor. 
commercial antihypertensive drug, Captopril. This suggests that the water extracts containing ACE inhibitor from $H$. marmoreus fruiting body has a clear antihypertensive effect in SHRs; at a dosage of $800 \mathrm{mg} / \mathrm{kg}$.

In conclusion, the antihypertensive ACE inhibitor in water extracts from Hypsizygus marmoreus (brown cultivar) fruiting body was purified with ultrafiltration, $\mathrm{C}_{18}$ solid phase extraction chromatography, and reverse-phase HPLC. A purified ACE inhibitor with an inhibitory activity $\left(\mathrm{IC}_{50}\right)$ of $0.19 \mathrm{mg} / \mathrm{mL}$ was obtained. The purified ACE inhibitor was found to be an oligo-peptide with the sequence LSMGSASLSP. Its molecular weight was estimated to be 567.3 Da, and the water-extract containing ACE inhibitor showed clear antihypertensive effect on a spontaneously hypertensive rat.

\section{References}

[1] T. Ikekawa, "Bunashimeji, Hypsizygus marmoreus antitumor activity of extracts and polysaccharides," Food Reviews International, vol. 11, no. 1, pp. 207-209, 1995.

[2] K. Mori, C. Kobayashi, T. Tomita, S. Inatomi, and M. Ikeda, "Antiatherosclerotic effect of the edible mushrooms Pleurotus eryngii (Eringi), Grifola frondosa (Maitake), and Hypsizygus marmoreus (Bunashimeji) in apolipoprotein E-deficient mice," Nutrition Research, vol. 28, no. 5, pp. 335-342, 2008.

[3] T. Matsuzawa, M. Sano, I. Tomita, H. Saitoh, and T. Ikekawa, "Studies on antioxidant effect of Hypsizigus marmoreus-I. Effects of Hypsizigus marmoreus for antioxidant activities of mice plasma," Yakugaku Zasshi, vol. 117, no. 9, pp. 623-628, 1997.

[4] T. Matsuzawa, H. Saitoh, M. Sano, I. Tomita, M. Ohkawa, and T. Ikekawa, "Studies on antioxidant effects of Hypsizigus marmoreus-II. Effects of Hypsizigus marmoreus for antioxidant activities of tumor-bearing mice," Yakugaku Zasshi, vol. 118, no. 10, pp. 476-481, 1998.

[5] E. Akavia, A. Beharav, S. P. Wasser, and E. Nevo, "Disposal of agro-industrial by-products by organic cultivation of the culinary and medicinal mushroom Hypsizygus marmoreus," Waste Management, vol. 29, no. 5, pp. 1622-1627, 2009.

[6] J.-H. Kim, D.-H. Lee, S.-C. Jeong, K.-S. Chung, and J.-S. Lee, "Characterization of antihypertensive angiotensin I-converting enzyme inhibitor from Saccharomyces cerevisiae," Journal of Microbiology and Biotechnology, vol. 14, no. 6, pp. 1318-1323, 2004.

[7] H. S. Choi, H. Y. Cho, H. C. Yang, K. S. Ra, and H. J. Suh, "Angiotensin I-converting enzyme inhibitor from Grifola frondosa," Food Research International, vol. 34, no. 2-3, pp. 177$182,2001$.

[8] A. Morigiwa, K. Kitabatake, Y. Fujimoto, and N. Ikekawa, "Angiotensin converting enzyme-inhibitory triterpenes from Ganoderma lucidum," Chemical and Pharmaceutical Bulletin, vol. 34, no. 7, pp. 3025-3028, 1986.

[9] D. H. Lee, J. H. Kim, J. S. Park, Y. J. Choi, and J. S. Lee, "Isolation and characterization of a novel angiotensin I-converting enzyme inhibitory peptide derived from the edible mushroom Tricholoma giganteum," Peptides, vol. 25, no. 4, pp. 621-627, 2004.

[10] K.-C. Koo, D.-H. Lee, J.-H. Kim, H.-E. Yu, J.-S. Park, and J.S. Lee, "Production and characterization of antihypertensive angiotensin I-converting enzyme inhibitor from Pholiota adiposa," Journal of Microbiology and Biotechnology, vol. 16, no. 5, pp. 757-763, 2006.

[11] J.-H. Jang, S.-C. Jeong, J.-H. Kim, Y.-H. Lee, Y.-C. Ju, and J.S. Lee, "Characterisation of a new antihypertensive angiotensin I-converting enzyme inhibitory peptide from Pleurotus cornucopiae," Food Chemistry, vol. 127, no. 2, pp. 412-418, 2011.

[12] S. Miyoshi, H. Ishikawa, T. Kaneko, F. Fukui, H. Tanaka, and S. Maruyama, "Structures and activity of angiotensin-converting enzyme inhibitors in an alpha-zein hydrolysate," Agricultural and Biological Chemistry, vol. 55, no. 5, pp. 1313-1318, 1991.

[13] Y. Saito, K. Wanezaki, A. Kawato, and S. Imayasu, "Structure and activity of angiotensin I converting enzyme inhibitory peptides from sake and sake lees," Bioscience, Biotechnology, and Biochemistry, vol. 58, no. 10, pp. 1767-1771, 1994.

[14] J. H. Kim, D. H. Lee, S. H. Lee, S. Y. Choi, and J. S. Lee, "Effect of Ganoderma lucidum on the quality and functionality of Korean traditional rice wine, Yakju," Journal of Bioscience and Bioengineering, vol. 97, no. 1, pp. 24-28, 2004.

[15] M. R. Rhyu, Y. J. Nam, and H. Y. Lee, "Screening of angiotensin I-converting enzyme inhibitors in cereals and legumes," Food Science and Biotechnology, vol. 5, pp. 334-337, 1996.

[16] B. Zanabaatar, M. K. Kim, G. S. Seo, Y. W. Lee, and J. S. Lee, "Screening and physiological functionality of Hypsizygus marmoreus (white cultivar) fruiting body," The Korean Journal of Mycology, vol. 39, no. 3, pp. 185-188, 2011.

[17] D. W. Cushman and H. S. Cheung, "Spectrophotometric assay and properties of the angiotensin-converting enzyme of rabbit lung," Biochemical Pharmacology, vol. 20, no. 7, pp. 1637-1648, 1971. 

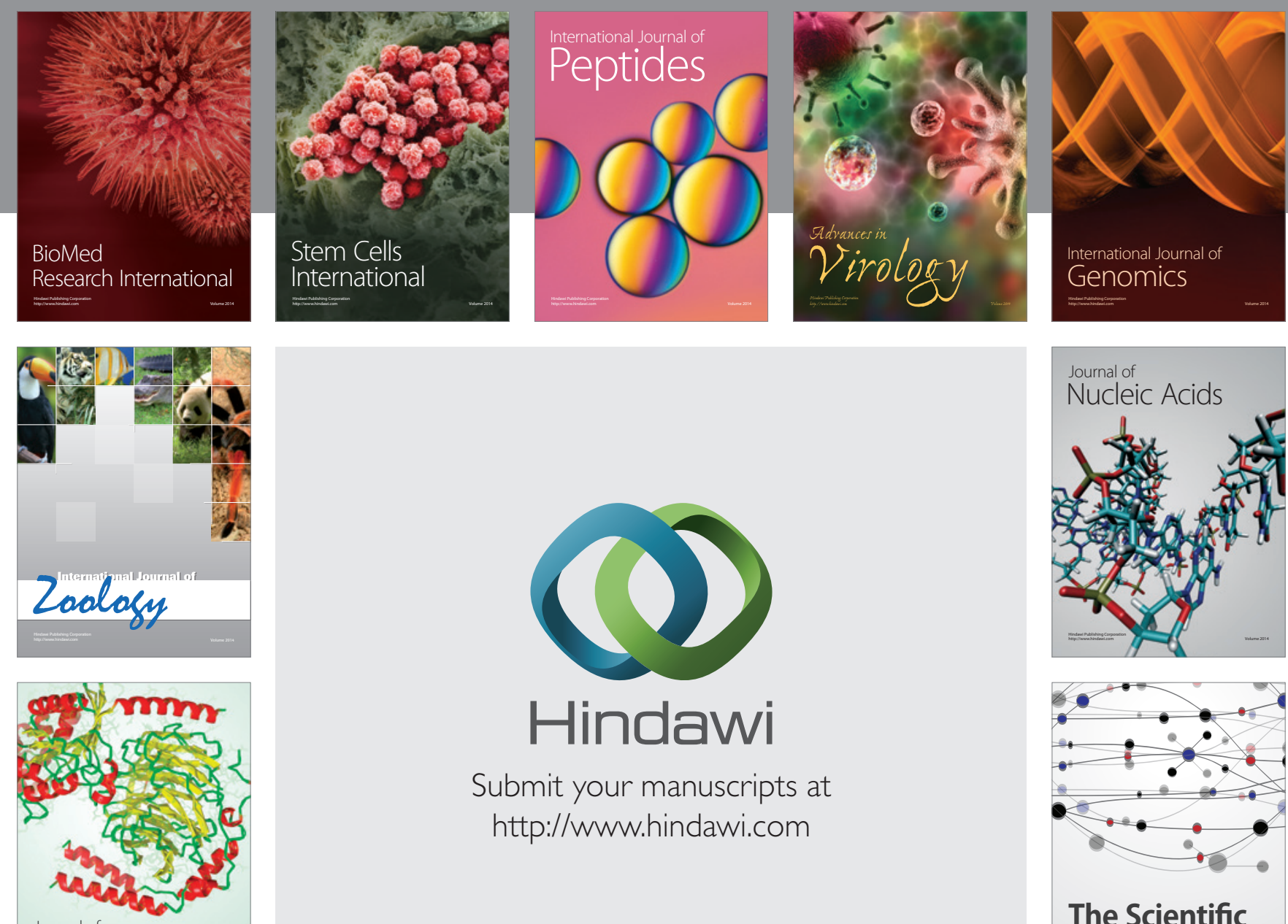

Submit your manuscripts at

http://www.hindawi.com

Journal of
Signal Transduction
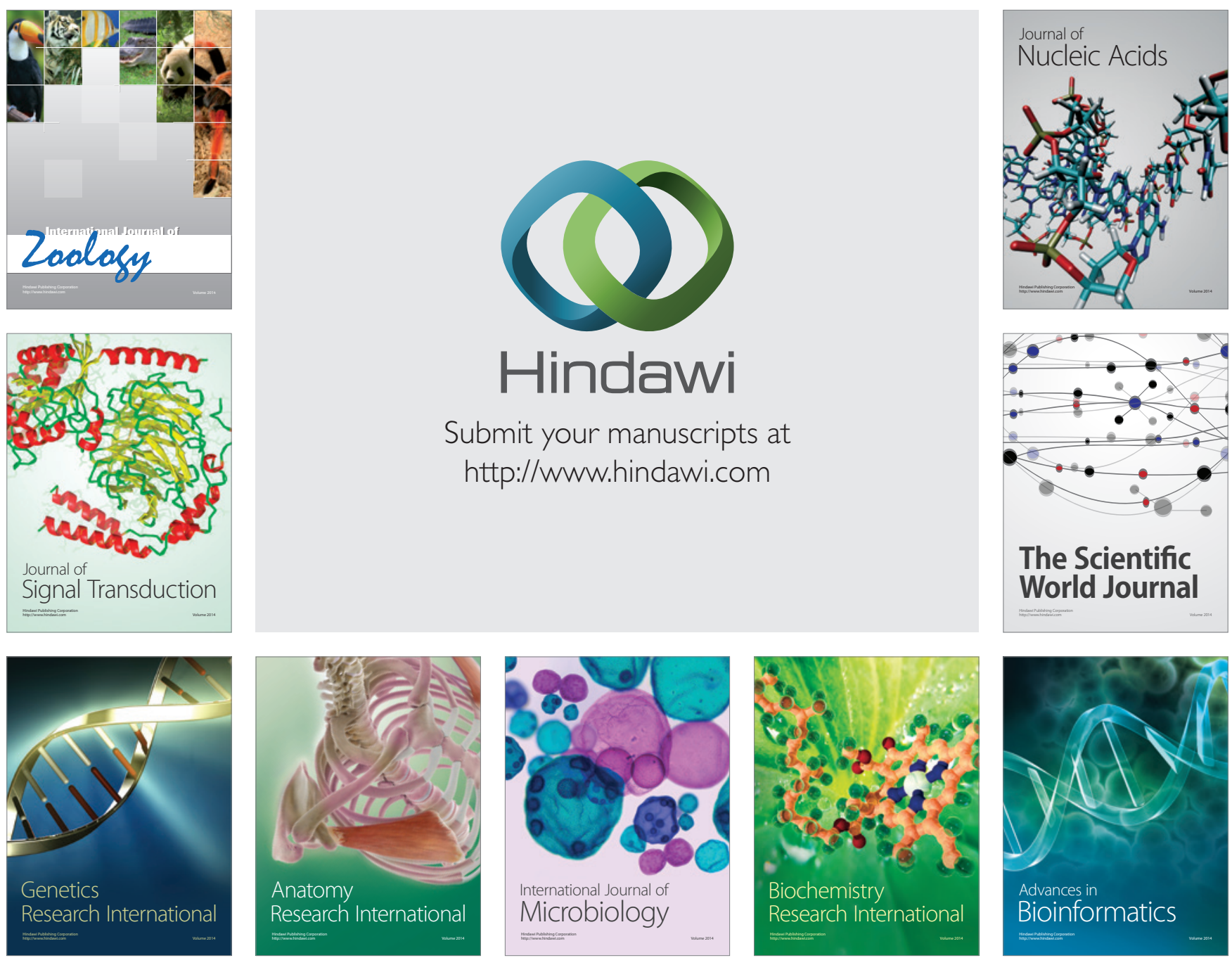

The Scientific World Journal
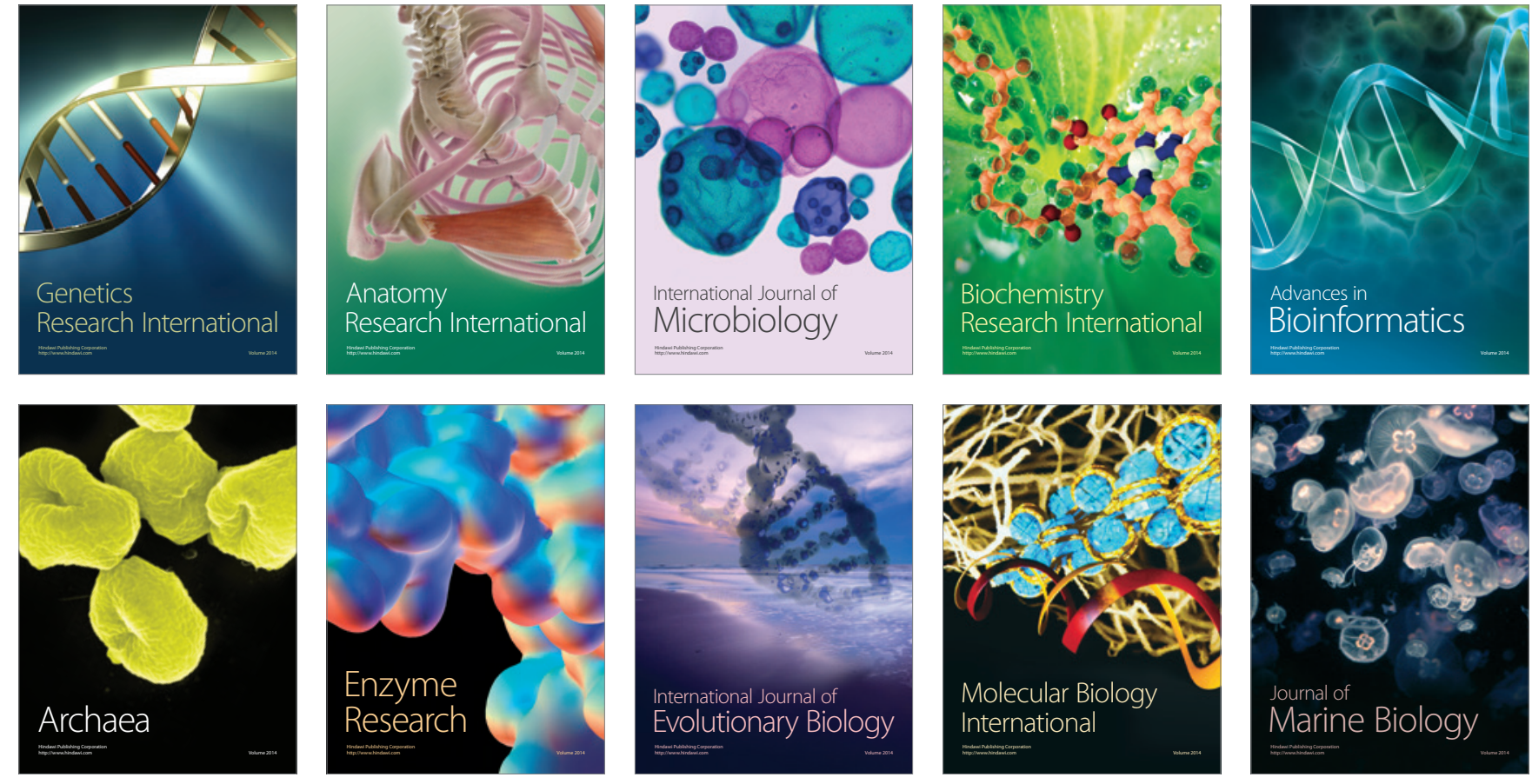